\title{
Methodological challenges in investigating nominalized infinitives in Spanish
}

Barbara Schirakowski

Freie Universität Berlin, Germany

https://doi.org/10.36505/ExLing-2017/08/0026/000328

\begin{abstract}
The present paper deals with Spanish nominalized infinitives (NI), a type of syntactic nominalization that comes in different subtypes. On the basis of argument realization, I will focus on two different forms, a more nominal and a more verbal one. Previous research has mainly focused on the internal syntax of NI, while the factors that govern the distribution of different subtypes have remained unclear. In the following, I will discuss some methodological challenges in investigating the latter issue and suggest acceptability judgment tasks as a possible solution. The results of two experiments show how the acceptability of NI is determined by the interaction of two factors: 1) argument realization and 2) event interpretation.
\end{abstract}

Key words: acceptability judgments, nominalized infinitives, Spanish

\section{Introduction}

Spanish allows a number of different NI, i.e. infinitives that are preceded by a determiner. For the present purpose, I will focus on only two forms and distinguish them on the basis of argument realization. Type $\mathrm{A}$ is the more nominal form and maps an argument of the verbal base onto a PP introduced by the preposition de, cf. (1). Type $\mathrm{B}$ is the more verbal form that selects a direct object, which is often, but not necessarily, a bare noun, cf. (2).
(1) el cantar de los pájaros
'DET singing of the birds'
(2) el cantar (las) coplas
'DET singing (the) songs'

Questions regarding the distribution of different subtypes and possible interpretations of NI have received little attention in the literature so far. The aim of this study is to bridge some gaps in this domain by presenting results from acceptability judgment experiments. At first, I will provide some necessary background information and then proceed to the methodology and the experimental results.

\section{Background}

Type A has received more attention in the literature, especially with regard to possible verb classes (e.g. Demonte \& Varela 1997). It has been noted that it can be built quite freely on intransitive verbs and that it is dispreferred with transitive ones. It is not entirely clear whether an argument of a

ExLing 2017: Proceedings of 8th Tutorial and Research Workshop on Experimental Linguistics, 19-22 June, Heraklion, Crete, Greece 
transitive verbal base can be mapped onto the PP position. Realization of the Theme argument is often considered 'ungrammatical' and realization of the Agent is rarely discussed.

From a semantic point of view, it is noteworthy that both type A and type B can occur as event-denoting nominals. More recently, the literature has become interested in the distinction between episodic and generic readings of deverbal nominalizations, cf. (3) vs. (4), and it has been noted that some (more) verbal forms show a preference for generic event interpretations (Iordăchioaia \& Soare 2015 among others).

(3) The observation of the neighbors was completed at midnight.

(4) The observation of the neighbors is a bad habit.

The central question of this paper can be formulated as follows: How does the interaction of argument realization (Theme vs. Agent) and event interpretation (episodic vs generic) influence the distribution of type A vs. $\mathrm{B}$ ?

\section{Methodology}

\section{Methodological considerations}

Difficulties in answering this question result from different factors. Spanish has a variety of derivational affixes that are highly productive and NI are by no means the default strategy for deverbal nominalization. They are often criticized in terms of style and usually occur in certain registers typical of written language. This background makes it difficult to reach reliable generalizations about their acceptability. Furthermore, to evaluate the impact of different interpretations, its seems essential to view NI in unambiguous contexts that evoke episodic or generic interpretations. Contexts that are available in corpora usually do not fulfil this requirement, but show all kinds of ambiguities. An experimental approach seems suitable to overcome these problems. Firstly, acceptability judgment experiments allow the NI to be embedded under matrix predicates that allow for only one interpretation. Secondly, judgments can be elicited on a multi-point scale which makes it easier to detect subtle differences between structures that are rather marginal, but not "equally bad" (e.g. Featherston 2007).

\section{Experimental design}

The two experiments that will presented here were conducted online and all participants were (monolingual) speakers of Peninsular Spanish. The experimental stimuli consisted of NI presented in contexts of one or two sentences. ${ }^{1}$ The verb lexemes were chosen based on token frequency and 
structural features. For example, to investigate whether type A prefers realization of the Agent or the Theme, the base had to belong to a verb class that allows the unspecified object alternation. The stimuli were presented along with distractor items in a ratio of 1: 1,5 and were counter-balanced as well as pseudo-randomized. Acceptability was measured on a 7-point Likert-scale. The data were analysed using the Wilcoxon signed-rank tests and a general linear mixed model (Schütze \& Sprouse 2013).

\section{Results}

Experiment 1 (16 participants / $192 \mathrm{NI}$ ) shows that type A, used with a transitive base, prefers realization of the Agent over the Theme, cf. (5) a. vs. b. A clear preference has, however, only been found for generic interpretations like those exemplified in $(5)(p<0,001)$.

a. El escribir del autor es obsesivo.

'DET writing of the author is obsessive.'

b. El escribir de un guion suele ser tedioso.

'DET writing of a screenplay is usually tedious.'

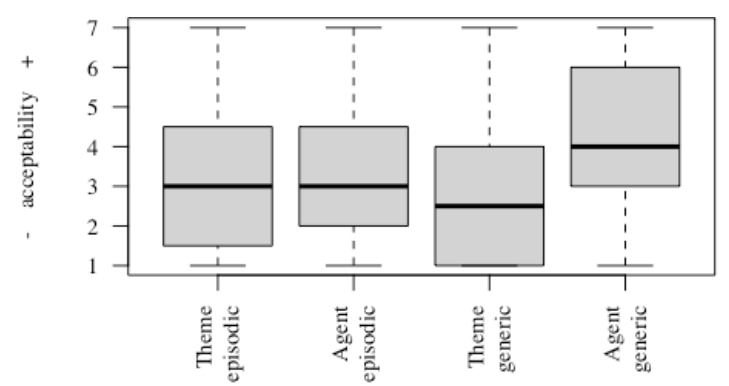

Figure 1. Experiment 1 - Type A (Theme vs. Agent; episodic vs. generic).

Experiment 2 (28 participants / $224 \mathrm{NI}$ ) shows that type B is far more acceptable than type $A$ in both episodic and generic readings $(p<0,001$ in each case). Furthermore, the results reveal that type B clearly prefers generic over episodic event interpretations, cf. (6) a. vs. b. $(p<0,01)$.

El utilizar productos químicos ...

'det using chemical products ...'

a. $\quad$... debería siempre ser el último remedio.

'... should always be the last resort.'

b. ... está avanzando por toda la ciudad.

'... is gaining ground throughout the city.' 


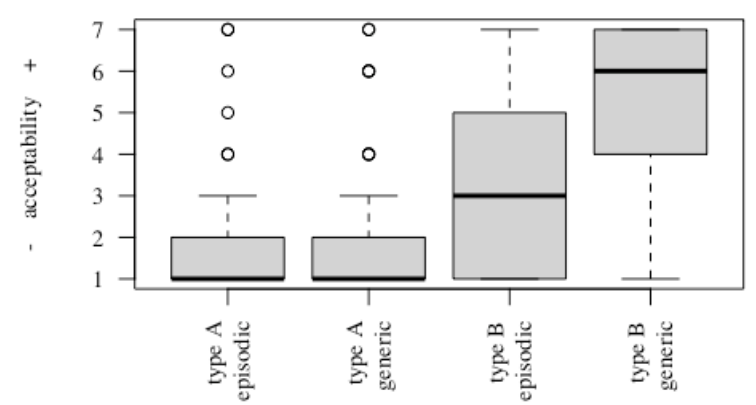

Figure 2. Experiment 2 - Type A vs. B; episodic vs. generic.

\section{Conclusions}

The acceptability judgment experiments have revealed fine-grained differences which informally collected data or corpus findings could not have yielded and show that NI can be better analyzed in terms of graded (un)acceptability than in terms of categorical (un)grammaticality. A potential drawback could be seen in the fact that only a limited number of verb lexemes (12 and 8) could be tested with this rather time-consuming method.

It appears that language-specific constraints regarding argument realization interact with possibly more general interpretational preferences of syntactic nominals that differ in their degree of nominalizations. This is indicated, at least, by the preference for generic readings attested for type B.

\section{Notes}

1. For reasons of space, the NI are presented here with only their matrix predicate and not the complete context.

\section{References}

Demonte, V., Varela S. 1997. Los infinitivos nominales del español. Signo y Seña 4, 125-154.

Featherston, S. 2007. Data in generative grammar: The stick and the carrot. Theoretical Linguistics 33, 269-318.

Iordăchioaia, G., Soare, E. 2015. Deverbal nominalization with the down operator. In Aboh, E.O., Schaeffer, J.C., Sleeman, P. (eds.) 2015. Romance Languages and Linguistic Theory 2013. Selected papers from „Going Romance“ Amsterdam 2013, 223-238, Amsterdam, John Benjamins.

Schütze, C.T., Sprouse, J. 2013. Judgment Data. In Podesva, R.J., Sharma, D. (eds.) 2013, Research Methods in Linguistics, 27-50, Cambridge, CUP. 